\title{
Metal-packaged fibre Bragg grating strain sensors for surface- mounting onto spalled concrete wind turbine foundations
}

\author{
M. Perry*a, G. Fusiek ${ }^{\mathrm{a}}$, I. McKeeman ${ }^{\mathrm{a}}$, P. Niewczas ${ }^{\mathrm{a}}$, M. Saafi ${ }^{\mathrm{b}}$ \\ ${ }^{a}$ Department of Engineering, University of Strathclyde, Glasgow, United Kingdom \\ ${ }^{\mathrm{b}}$ Department of Engineering, Lancaster University, Lancaster, United Kingdom \\ *m.perry@strath.ac.uk
}

\begin{abstract}
In this work, we demonstrate preliminary results for a hermetically sealed, metal-packaged fibre Bragg grating strain sensor for monitoring existing concrete wind turbine foundations. As the sensor is bolted to the sub-surface of the concrete, it is suitable for mounting onto uneven, wet and degraded surfaces, which may be found in buried foundations. The sensor was able to provide reliable measurements of concrete beam strain during cyclic three- and four- point bend tests. The strain sensitivity of the prototype sensor is currently $10 \%$ of that of commercial, epoxied fibre strain sensors.
\end{abstract}

Keywords: concrete foundations, cracking, fibre Bragg gratings, structural health monitoring

\section{INTRODUCTION}

The degradation of reinforced-concrete wind turbine foundations is a frequently modeled, but rarely measured parameter which fundamentally influences design and construction [1]. Over time, dynamic wind loads and bolt prestress can cause localised tension in the concrete, leading to cracks which span the foundation plinth [2]. A common approach for measuring stress and cracking within large reinforced-concrete structures is to attach strain sensors to the embedded reinforcing rebars, but this solution is only plausible for new constructions [3].

For existing foundations, retrofitted, surface-mounted strain sensors may provide some indication of structural integrity. Fibre Bragg grating (FBG) strain sensors are often used in other civil applications as they are small, chemically inert and can be serially multiplexed [4]. Unfortunately, the provision of suitable packaging and attachment methods to ensure long-term sensor reliability remains a challenge [5]. Designing sensors for the surfaces of wind turbine foundations is particularly challenging as the structure is buried and exposed to the damaging effects of soil shear and water [6]. Furthermore, strong adhesion and good strain transfer are difficult to achieve with conventional sensor-bonding methods such as epoxy, as excavated concrete surfaces may be wet, uneven from cracking and highly unstable due to spalling [7].

In this work, we present preliminary results for a rugged, hermetically sealed, metal-packaged fibre sensor, that is suitable for bonding to a spalled concrete foundation. The sensor is characterised and then attached to the surface of a reinforced-concrete beam and placed under dynamic three- and four- point bend tests. The strain response is verified using commercially available displacement and strain sensors. With further work and design iterations, these sensors may provide a promising solution for crack monitoring in buried foundation environments.

\section{SENSOR DESIGN AND FABRICATION}

\subsection{Overview}

The layout of the packaged sensor is shown in Figure 1a. A $10 \mathrm{~mm}$ section of a copper-alloy coated optical fibre was stripped to allow side-writing of a type-I FBG. The bare section was enveloped and brazed into a $20 \mathrm{~mm}$ long kovar capillary (outer diameter $0.7 \mathrm{~mm}$ ) using a two-turn induction coil, as outlined in previous work [8]. The capillary was then brazed to a $0.1 \mathrm{~mm}$ thick steel 'strain plate' (dimensions $2.5 \mathrm{~cm} \mathrm{x} 15 \mathrm{~cm}$ ). The strain plate was cleaned of any oxidisation and armoured cable was slotted over the addressing fibre to protect it from mechanical shear. For this initial prototype, sections of the brazed sensor and armoured cable were coated in silicone sealant. In future iterations, this will be replaced by a metal cage. 
The sensor was attached to the middle of a reinforced concrete beam $(10 \mathrm{~cm}$ x $10 \mathrm{~cm}$ x $110 \mathrm{~cm})$. Holes were drilled in to the beam to allow two, $10 \mathrm{~cm}$ square, steel 'support plates' (approx. $1 \mathrm{~mm}$ thick) to be fixed to the beam using rawl bolts. As the support plates are bonded to the holes within the beam, they provide a flat and sturdy platform for the strain plate, which will not be affected by spalling of the concrete top surface. While it was not required in this case, the support plates may also be of different thicknesses to allow uneven surfaces to be levelled. The strain plate was welded across the bolted support plates using an electrical resistance spot-welder.

a)

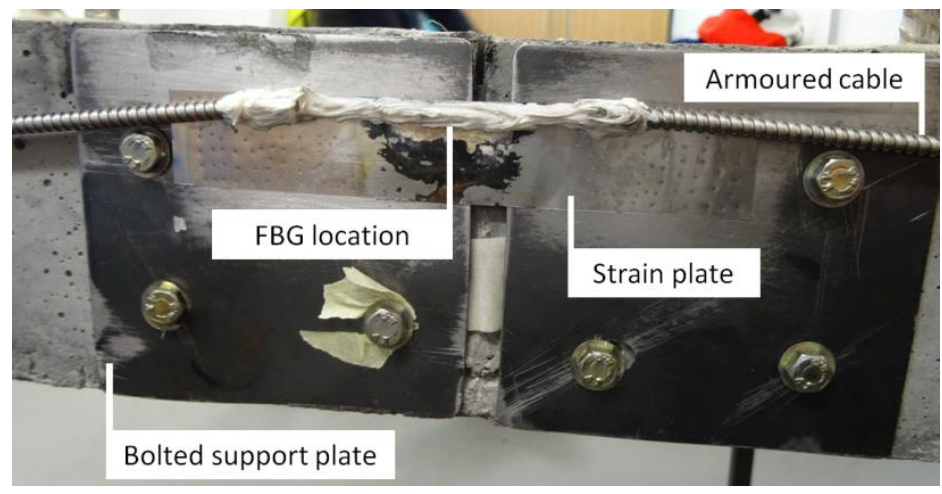

b)

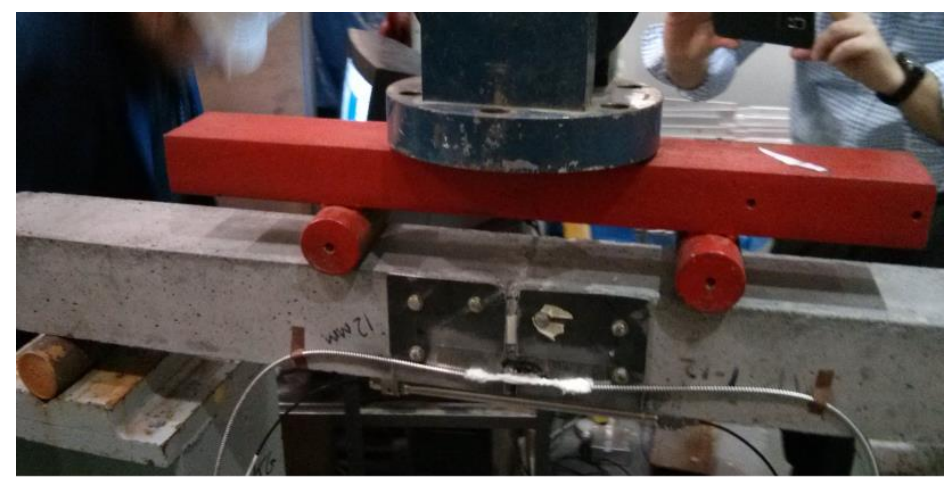

Figure 1. a) Layout of the sensor and b) sensor attached to concrete beam during four-point bend test.

\subsection{Characterisation}

The strain, $\varepsilon$, and temperature, $T$, dependence of an FBG sensor's Bragg wavelength shift, $\lambda_{B}$, are described by:

$$
\frac{\Delta \lambda_{\mathrm{B}}}{\lambda_{\mathrm{B}}}=k_{\varepsilon} \varepsilon+k_{T} \Delta T
$$

where $k_{\varepsilon}$ and $k_{T}$ are the FBG's strain and temperature sensitivity respectively. In this work, the temperature sensitivity of the metal-packaged sensor was characterised in an environmental chamber between $-4{ }^{\circ} \mathrm{C}$ and $35{ }^{\circ} \mathrm{C}$. Figure 2 shows that the temperature sensitivity of the packaged sensor is $15.5 \times 10^{-6} /{ }^{\circ} \mathrm{C}$. This is higher than the value for a bare $\mathrm{FBG}$ $\left(0.8 \times 10^{-6} /{ }^{\circ} \mathrm{C}\right)$ due to the additional thermal expansion of the attached steel parts.

\subsection{Testing method}

Prior to testing, the concrete beam was further instrumented with an epoxied, commercial FBG patch sensor. The commercial sensor is comprised of an FBG, sandwiched between several layers of plastic and epoxy. The patch sensor also contains a debonded FBG for temperature compensation. The instrumented concrete beam was installed into a loading apparatus for three- and four- point bend testing, as shown in Figure 1b. In the three point bend test, downward force was applied to the top surface of the centre of the beam. In the four-point bend test, forces were applied $15 \mathrm{~cm}$, either side of the centre. The stroke (displacement) and force applied to the top surface of the beam were measured by the apparatus, while an LVDT monitored deflection of the lower surface. Cyclic displacements of $0.2-3 \mathrm{~mm}$, and cyclic loads of $0.4-7.5 \mathrm{kN}$ were applied to the beam. FBG sensors were interrogated at a rate of $2 \mathrm{~Hz}$ with a commercial interrogator ( $1 \mathrm{pm}$ wavelength resolution, equivalent to approximately $1 \mu \varepsilon$ ). 


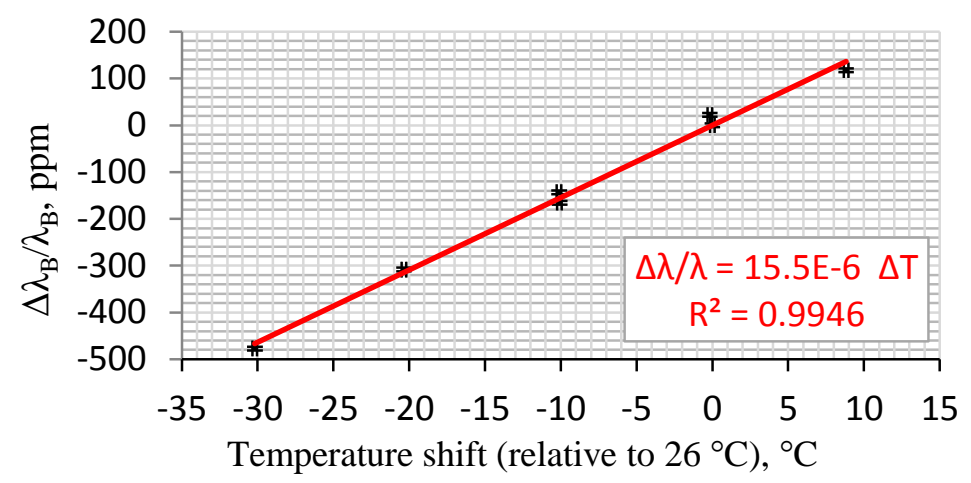

Figure 2. Temperature sensitivity of the packaged FBG sensor between $-4{ }^{\circ} \mathrm{C}$ and $35{ }^{\circ} \mathrm{C}$.

\section{RESULTS}

\subsection{Strain response}

Figure 3 shows the response of the commercial and metal-packaged strain sensors during a $5 \mathrm{kN}$ four-point bend test. Both sensors are able to detect concrete strains without any hysteretic behaviour, but the metal-packaged strain sensor appears to have a lower sensitivity. The overall relationship between the applied force and measured strain during a three-point bend test, shown in Figure 4, reveals that the strain transfer of the metal-packaged sensor is approximately $12 \%$ of the commercial sensor. This low strain transfer may arise as the capillary is only bonded to the strain plate from one side, rather than enveloped [9]. Plastic deformation of the strain plate may also have contributed to strain loss, and so thicker strain plates may be trialed in future work.
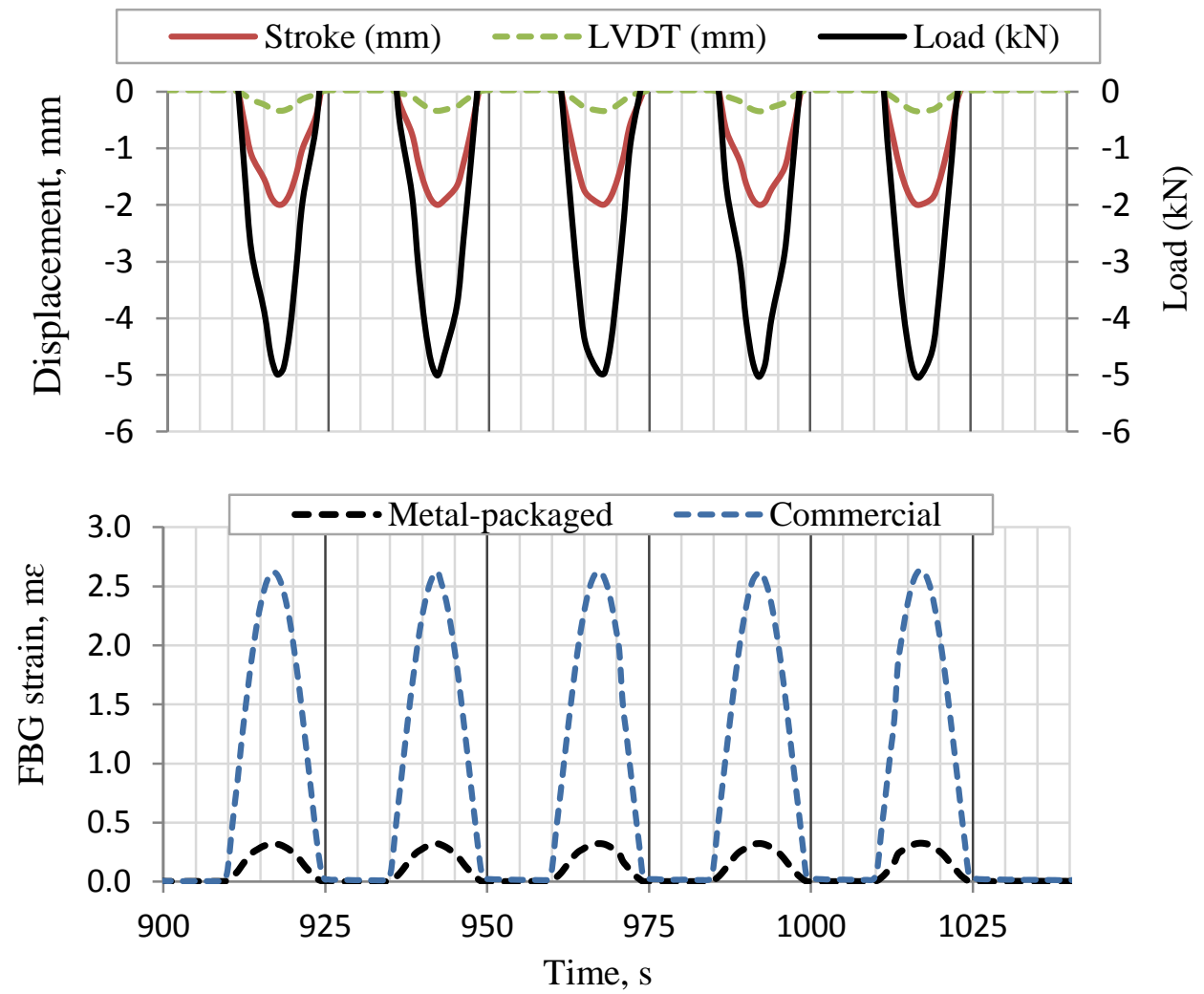

Figure 3. Response of metal-packaged and commercial FBG strain sensors during four-point bend test (5 kN load) 


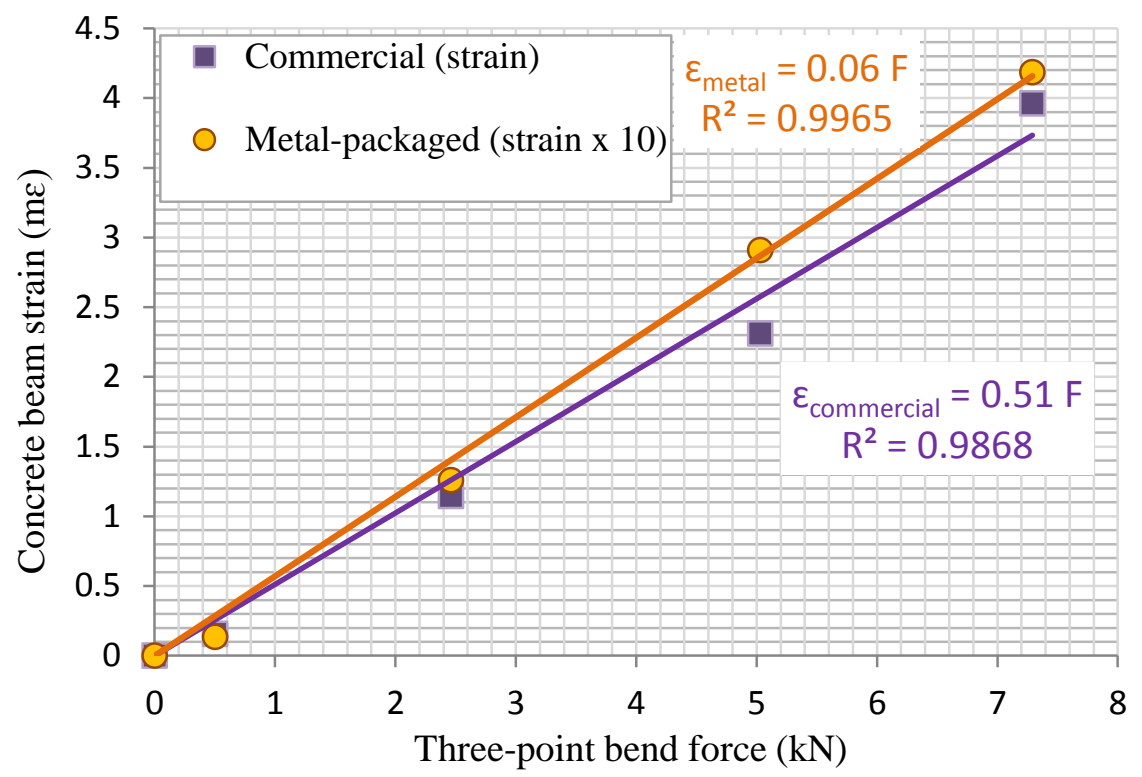

Figure 4. Strain measured by metal-packaged and commercial patch sensor as a function of force during three-point bend test. Note that the metal-packaged sensor strain response has been multiplied by 10 for clarity.

\section{CONCLUSIONS}

In this work, we have demonstrated a prototype metal-packaged fibre Bragg grating strain sensor for surface mounting onto spalled concrete foundations. By bonding to the sub-surface of the concrete, the sensor was able to provide reliable strain measurements of a concrete beam during cyclic three- and four- point bending tests. In this preliminary work, the bespoke sensor's strain sensitivity was approximately $10 \%$ of that of a commercial fibre strain sensor. With further design iterations, this sensor may provide long-term, accurate measurements of cracking in buried concrete foundations.

\section{ACKNOWLEDGEMENTS}

This work is part of a large scale research project to develop structural health monitoring systems for onshore wind farms, and was funded and supported by Scottish Power Renewables (SPR) and Scottish and Southern Energy (SSE).

\section{REFERENCES}

[1] Hau, E. [Wind Turbines: Fundamentals, Technologies, Applications, Economics], Springer, New York (2006)

[2] M Hassanzadeh, "Cracks in onshore wind power foundations: Causes and consequences", Elforsk 11:56 (2012).

[3] Ou, J., Zhou, Z. and Zhao, X., "Encapsulation Techniques for FBGs and Smart Monitoring for Bridges with FBG Sensors", Proc. 4th International Workshop on Structural Health Monitoring, 180-187 (2003)

[4] Li, H.N., Li, D.S. and Song, G.B. "Recent applications of fiber optic sensors to health monitoring in civil engineering”, Engineering Structures, 26(11), 1647-1657 (2004).

[5] Miller, J.W. and Mendez, A., "Fiber Bragg Grating Sensors: Market Overview and New Perspectives", [Fiber Bragg Grating Sensors: Recent Advancements, Industrial Applications and Market Exploitation], 313-320 (2014).

[6] Kurkjian, C.R. and Matthewson, M.J. "Strength degradation of lightguide fibres in room temperature water", Electronics Letters 32(8), 761-762 (1996).

[7] Lin, Y.B., Chang, K.C., Chern, J.C. and Wang, L.A., "The health monitoring of a prestressed concrete beam by using fiber Bragg grating sensors", Smart Materials and Structures 13(4), 712-718 (2004).

[8] Perry, M., Niewczas, P., Johnston, M., Cook, K. and Canning J., "Induction Brazing of Type-I Fiber Bragg Gratings Into Kovar Ferrules Exploiting Curie Transition”, IEEE Sensors 13(2), 816-823 (2013).

[9] Li, H.N., Zhou, G.D., Liang, R. and Li, D.S., "Strain transfer coefficient analyses for embedded fiber Bragg grating sensors in different host materials", Journal of engineering mechanics, 135(12), 1343-1353 (2009). 